\title{
Understanding the Experiences of Relocatees during Forced Relocation in Chinese Urban Restructuring
}

\section{Xin Li, Maarten van Ham \& Reinout Kleinhans}

To cite this article: Xin Li, Maarten van Ham \& Reinout Kleinhans (2018): Understanding the Experiences of Relocatees during Forced Relocation in Chinese Urban Restructuring, Housing, Theory and Society, DOI: 10.1080/14036096.2018.1510432

To link to this article: https://doi.org/10.1080/14036096.2018.1510432

ఠ

(C) 2018 The Author(s). Published by Informa

UK Limited, trading as Taylor \& Francis Group.

曲 Published online: 31 Oct 2018.

Submit your article to this journal $\pi$

View Crossmark data $₫$ 


\title{
Understanding the Experiences of Relocatees during Forced Relocation in Chinese Urban Restructuring
}

\author{
Xin Lia,b,c, Maarten van Ham ${ }^{\mathrm{b}, \mathrm{d}}$ and Reinout Kleinhans ${ }^{\mathrm{b}}$ \\ aNortheast Institute of Geography and Agroecology, Chinese Academy of Sciences, Changchun, China; \\ ${ }^{b} \mathrm{OTB}$ - Research for the Built Environment, Faculty of Architecture and the Built Environment, Delft \\ University of Technology, Delft, The Netherlands; 'University of Chinese Academy of Sciences; ${ }^{\text {dSchool of }}$ \\ Geography \& Geosciences, Irvine Building, University of St Andrews, Scotland, UK
}

\begin{abstract}
Despite the massive forced relocation of residents during urban restructuring in China, there is no systematic overview regarding how residents experience the process and its outcomes. Most studies concerning urban restructuring in China directly equate forced relocation with displacement, which has a negative connotation. This predominantly negative view overlooks the multifaceted effects of forced relocation on relocatees. This paper aims to provide a better understanding of relocatees' experiences during urban redevelopment in China by establishing a conceptual model in which the time sequence of events and their context are central. It conceptualizes forced relocation as a process with various and changing socio-spatial implications over time, and as a specific type of residential mobility that occurs in the context of urban restructuring. As such, the conceptual model divides the process of forced relocation into a pre-demolition stage, a transitional stage and a post-relocation stage and investigates the social, economic, physical, psychological and behavioural dimensions of the experiences of relocatees as affected by the macro and micro context. The conceptual model is used to structure the analysis of the existing literature about residents' experiences and to subsequently identify the gaps in the literature that should be addressed in future studies of forced relocation in the Chinese context.
\end{abstract}

\section{ARTICLE HISTORY}

Received 16 September 2016

Accepted 30 July 2018

\section{KEYWORDS}

Experience of relocatees; forced relocation; urban restructuring; residential mobility; displacement; China

\section{Introduction}

Driven by market mechanisms and economic growth, since 1978, developers and entrepreneurial local governments in China have formed pro-growth coalitions, which have embarked on extensive urban housing demolition and redevelopment on profitable locations, featuring large-scale forced rehousing of residents. Local governments or developers inform residents that their neighbourhoods are going to be demolished, and residents have to move involuntarily, regardless of their moving intention. This has resulted in the movement of residents from their original neighbourhoods to other "destination" neighbourhoods. For example, in the city of Shanghai, roughly 1.1 million 
households were relocated between 1995 and 2012, and 72 million square metres of housing were demolished. In 2008, in parallel with the local-state-initiated residential redevelopment projects, the central Chinese government initiated the first round of national Shantytown Redevelopment Projects (SRPs), which aims to improve the living conditions of low-income residents and to stimulate the depressed housing market. In 2013, the central government triggered the second round of large-scale urban clearance projects. It is estimated that between 2013 and 2017 approximately 10 million households will have been affected (Li, Kleinhans, and Van Ham 2018; The State Council of PRC 2013).

However, compared with the sheer numbers of affected residents in China, the research on the experiences of relocatees during forced relocation in China is still limited. Outside Europe and the United States of America, where a significant body of research on forced relocation has been conducted, little is known about the micro perspective, i.e. individual relocatees' experiences and coping strategies (behaviours and perceptions) with forced relocation. Furthermore, several key elements in the discussion have hindered the possibility to further reveal the diversity and the dynamics that underlies relocatees' experiences in the Chinese context. First of all, the forced relocation of residents, which often occurs in urban restructuring projects around the world, has been criticized for having predominantly negative effects on residents and their communities (e.g. Atkinson 2000; Davidson 2008). Several scholars have blamed large-scale property-led restructuring projects in China for causing displacement of lowincome residents (He 2007, 2012; La Grange and Pretorius 2016; Gong 2012). However, other studies have demonstrated real improvements in the relocatees' (perceived) living conditions after relocation ( $\mathrm{Li}$ and Song 2009; Wu 2004a, 2004b). Thus, in general, it appears that the effects of forced relocation on relocatees during urban restructuring projects are diverse and not necessarily only negative; they may be simultaneously positive in other respects. Second, some studies and news reports have shown the conflicts and tensions between relocatees and local governments or developers from a macro-, meso- or political-economic perspective (He 2012; Hin and Xin 2011; Qian and He 2012; Sichuan News, 2009; Weinstein and Ren 2009), which gives an impression that the role of residents in redevelopment projects is always passive. This impression can lead to disregarding the active role and agency of relocatees before and during urban redevelopment and forced relocation. Third, current studies about China mostly treat forced relocation as a single event, which overlooks the sequence of events that relocatees may experience during and after forced relocation.

This paper therefore aims to provide a better understanding of the experiences of relocatees during urban redevelopment in China from the individual and household perspective. In particular, this is achieved by (1) establishing a conceptual model in which the time sequence of events and their context are central, and by (2) analyzing the existing research on the implications of forced relocation for residents in urban restructuring areas in China. As such, the conceptual model works as a structuring element for the review of the literature. It divides the process of forced relocation into three chronological stages: the pre-demolition stage, the transitional stage and the postrelocation stage.

The following section will discuss the literature on forced relocation and displacement in general and propose a conceptual model for studying forced relocation. Section 
3 will provide the specific context of forced relocation in urban China, while Section 4 will apply three stages in the conceptual model for a better understanding of relocatee's experiences by reviewing the current literature on Chinese forced relocation. The final section offers our conclusions and suggestions for further research.

\section{The Experiences of Relocatees in Urban Restructuring}

Although this paper focuses on forced relocation in urban China, we will first briefly discuss the international literature to establish a conceptual model that offers a better understanding of the experiences of relocatees. The international literature has advanced in studying this matter, which can help to improve understanding with regard to related Chinese studies. Forced relocation refers to the process by which residents are forced to move from their original dwellings and neighbourhoods to new destination neighbourhoods, due to urban restructuring projects. Forced relocation of residents is usually initiated and implemented top-down by local governments, housing associations or developers. Residents who are forced to move (relocatees) are often involuntarily involved in urban restructuring. This is commonly regarded as displacement. "Displacement" is defined as the state which:

occurs when any household is forced to move from its residence by conditions that affect the dwelling or its immediate surroundings, and that: 1) are beyond the household's reasonable ability to control or prevent; 2 ) occur despite the household's having met all previously imposed conditions of occupancy; and 3) make continued occupancy by that household impossible, hazardous, or unaffordable (Grier and Grier 1980, 8).

Hence, relocatees and displacees are both forced to move involuntary and they have little or no control over the decision-making processes underlying urban redevelopment projects or gentrification (Kleinhans and Kearns 2013).

However, while the terms forced relocation and displacement are applied to related contexts and situations and both have predominantly negative connotations, we argue that the term forced relocation allows for outcomes that are not by definition negative. Displacement exclusively focuses on the downsides caused by "the involuntary residential dislocation" process of gentrification (Marcuse 1985, 205), including worsened living conditions, harassment by landlords or financial constraints caused by rising housing rents (Atkinson 2000; Freeman and Braconi 2004; Newman and Wyly 2006). However, urban restructuring policies in many countries, such as the United States, France and the Netherlands include legally established compensation mechanisms for forced relocatees, whereas compensation is non-existent in the case of gentrification-induced forced relocation (Kleinhans and Kearns 2013).

We will now explain several features of forced relocation that should be recognized while studying the experiences of relocatees, because they are conditional for various outcomes. Firstly, forced relocation is a process that changes in content over time. The content of forced relocation, including policies and implementation, stakeholders and their interaction, social groups targeted or the aims of redevelopment, differ over time (Goetz 2013). A redevelopment project consists of different stages with different periodical targets as it proceeds over time. For each target at each stage, it involves different stakeholders, social groups and interactions between them. Goetz (2013) also 
emphasizes the significance of "time" and the "micro and macro context" in exploring relocatees' experiences, by showing how the implementation of the project, the local housing market, related policies, and the family situation cause changes to relocatees' experiences. Thus, the evaluation of the outcomes of forced relocation should take into account the nature of variability, rather than focusing on a static event or unitary measurement. Some studies have found that the experiences of relocatees are dynamic and vary as forced relocation proceeds (Goetz 2013; Popkin et al. 2004).

Secondly, forced moves of residents can be considered a specific type of residential mobility which occurs in the context of top-down imposed relocation decision. Relocatees may have behavioural and psychological experiences that are similar to voluntary movers, such as previously existing intentions to move, the search for (replacement) housing and the housing choice. In some cases, local governments or housing authorities provide relocatees with special housing options in terms of the location, size, floor, and rental fees/housing price, in order to improve residential satisfaction and promote a smooth relocation and redevelopment process. Relocatees also face similar macro and micro constraints related to the housing market context, their socioeconomic status, such as income and education, and their individual ability to search for information on housing market (Kearns and Mason 2013, 189, Bolt and Van Kempen 2010, 161-164, Posthumus and Kleinhans 2014; Popkin et al. 2004). Thus, to understand the extent to which residents are forced to move, how and why residents have different perceptions of forced relocation, and how this leads to different outcomes, it is necessary to investigate the experiences of relocatees from a micro and residential mobility perspective (Doff and Kleinhans 2010; Popkin et al. 2004). Some studies have found that some residents who expressed a pre-relocation intention to move also reported a higher level of post-relocation dwelling improvement compared to those who had no intention to move (Kleinhans and Van der Laan Bouma-Doff 2008). Other studies have found that high-income relocatees are less likely to move into low-income neighbourhoods, while people from ethnic minority groups tend to relocate to ethnically concentrated neighbourhoods, regardless of their level of income or education (Doff and Kleinhans 2010; Bolt and Van Kempen 2010). These findings show that it is simplistic to label (the outcomes of) forced relocation by definition as negative, because this ignores the complexity of relocatees' pre- and post-relocation housing behaviour and moving intentions, which may resemble that of regular movers without any top-down pressure to move.

Thirdly, the institutional, economic and social contexts in which forced relocation is embedded, as well as relocatees' personal characteristics, also affect their experiences (Chen and Lai 2013; He 2014). Forced relocation is accompanied by constraints but also includes various social, economic and cultural resources unique to relocatees. For example, compensation criteria and the time span of the relocation process determined by local governments, affect relocatees' mobility experience. Whether the forced relocation is enacted by the governments or market forces can influence relocatees' experience differently, since developers might have more freedom on compensation criteria than local governments. In addition, the social context, such as social movements or media demands for public participation in urban restructuring projects, also affects the experience of relocatees (He 2014). Other research in this context has emphasized the importance of the social, psychological and cultural physical dimensions of relocatees' 
experience (Cernea 1997; Downing and Downing 2009; Scuddder and Colson 1982; Xi and Hwang 2011). Local housing market plays a significant role with regard to relocatees' housing options and choices. Relocatees facing a relaxed housing market might encounter fewer challenges and competition than in a tight housing market (see also Section 3).

Although relocatees are forced to move, they have a certain amount of "freedom" and agency to make their own decisions, even if limited within the criteria of compensation schemes (Manzo, Kleit, and Couch 2008), which may help to alleviate the stress and disruptions resulting from forced relocation. Relocatees may develop positive coping strategies in response to the relocation-based stress, rather than passively accepting everything that forced relocation imposes on them (Posthumus and Kleinhans 2014; Weinstein and Ren 2009). Some studies have found that those who feel in control or positive about forced relocation may end up more satisfied with their new dwelling. Relocatees may perceive forced relocation as a chance to improve their housing situation because compensation may effectively increase their options on the local housing market (Allen 2000, 450; Kleinhans 2003, 487). However, others cannot effectively respond to or make choices during forced relocation, especially those who have limited resources and face multiple life problems, such as ageing people, people on low incomes or with low levels of education, or particular ethnic groups (Kleinhans 2003; Posthumus and Kleinhans 2014; Popkin et al. 2004).

The literature discussed above has demonstrated that time/stage, the context and the various dimensions of relocatees' experience are highly significant issues. Therefore, we present a conceptual model for understanding the experiences of individual relocatees during forced relocation in urban restructuring (Figure 1). Breaking down the time dimension reveals the sequence of events that individuals/households may experience and various factors that affect the experiences at different stages. The model divides forced relocation into three stages: the pre-demolition stage, the transitional stage and the post-relocation stage. First of all, the pre-demolition stage refers to the stage when the original neighbourhood has not yet been demolished; relocatees still live in it. They are informed that their neighbourhood will be demolished and that they have to move out. In this stage, reaching an agreement on compensation between relocatees and the evictors is the main focus (Chen and Lai 2013; Hu et al. 2015). The nature and forms of compensation will be discussed in Section 3.

Second, the transitional stage means that relocatees have moved out of their original neighbourhood, live in temporary accommodation but have not been rehoused into their final housing situation yet. In some countries, such as China this is a necessary and normal stage. However, in Western Europe and the USA this stage is rare. In other words, adding the transitional stage to the conceptual model is an added value for studying the Chinese context. In China, the length of this stage is closely related to the performance and management of local governments and developers who construct the relocation neighbourhoods to which the residents can move (see Section 4.3).

The third stage is the post-relocation stage, which means that relocatees have moved into a "permanent" housing situation and start with adapting their daily routines and habits. Important factors are the new housing, the neighbourhood, social networks, but also transportation and employment. 


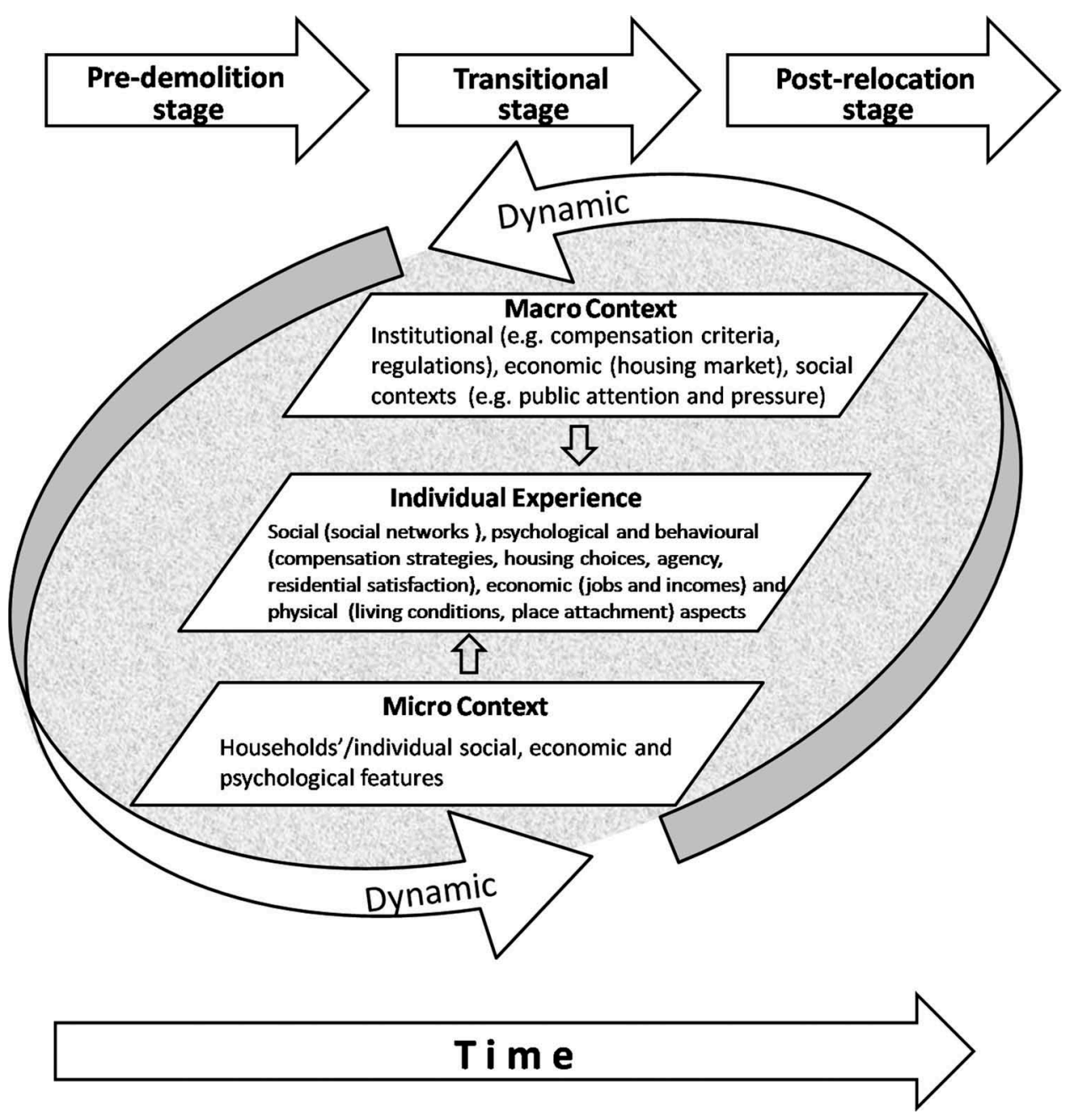

Figure 1. Conceptual model.

It is crucial to divide the context into macro and micro levels. The macro level concerns the institutional, social and economic context in which forced relocation and urban restructuring are embedded, and conceives of the movement of relocatees as a specific type of residential mobility. In China, huge number of people from various social groups have been affected by the wave of capital accumulation through continuous spatial (re)development and consumption. Obviously, various levels of government and developers strongly affect the nature and course of the relocation process, as a result of their (changing) roles, resources and interests (Li, Kleinhans, and Van Ham 2018). The same applies to rules and regulations on various administrative levels, and the state of the local housing market.

The micro level concerns the individual's and the household's socioeconomic features and preferences. As with regular movers, relocatees' experiences occur across the social, physical, economic, behavioural and psychological dimensions. These dimensions 
change over time within the context of forced relocation. For example, the levels of psychological stress vary in intensity throughout the relocation stages, associated with uncertainty regarding compensation, temporary housing, the final destination and other issues. In Section 4, we use the conceptual model to discuss the experiences of relocatees at each stage, based on the available literature. We also demonstrate what has been evident and what is missing in current research. The following section will explain in more detail the background of forced relocation in urban China.

\section{The Macro Context of Forced Relocation in Urban China}

In order to give a clear and reproducible literature overview, we did a search and analysis of the current literature. We used Scopus and Web of Science to conduct a literature search with combinations of four themes and related key words: (1) China OR urban China OR Guangzhou, Shanghai, Beijing (Chinese cities that often appear in related literature); (2) forced relocation OR forced movement OR eviction OR involuntary movement OR displacement or demoli*, etc.; (3) urban redevelopment OR urban restructuring, etc.; (4) forced mover* OR relocatee* OR involuntary mover*. We mainly (but not exclusively) focus on papers published in English, as including papers written in Chinese would limit accessibility to readers who are fluent in this language. While we searched for Chinese articles by using a popular Chinese search engine (CNKI), we found that Chinese papers mostly relate to other issues than the experiences of forced relocatees, such as laws, policy, regulations, techniques for dwelling size measurement, urban economics and real estate market development. However, we identified some dissertations with regard to relocatees' experiences during forced relocation (Gong 2012; Luo, 2012; Ma 2012), which are included in the review.

After checking titles and abstracts, we identified 52 articles in English (published between 1995 and 2017) on forced relocation and urban restructuring in China, which is a relatively small number considering the scale of forced relocation in China. We categorized these articles based on relocation stage and the main issues covered (such as interactions between different stakeholders, implementation of specific urban redevelopment projects, relocatees' coping strategies, experiences and outcomes). Most articles use specific projects to illustrate how local governments, developers and residents interact with each other during the redevelopment, which provides an opportunity to reveal the macro institutional, economic and social contexts with regard to relocatees' experiences.

In China, many conflicts related to forced relocation arise from the interactions between homeowners and local governments or developers. Most studies, news reports and regulations concerning forced relocation in China focus on homeowners - unlike the literature on Western Europe and the United States, which predominantly focuses on renters living in social or public housing. In the United States and Western Europe, renters get compensation from local authorities or housing associations (Goetz 2016, Kleinhans and Kearns 2013), which is quite different with the experiences of their counterparts (renters) in China, who are usually excluded during the redevelopment process. This difference arises due to the fact that homeownership in China determines residents' accessibility to different social resources, such as compensation during urban redevelopment. In this paper, we focus on the experiences of homeowners. Local 
governments and developers need to reach agreements with homeowners about compensation before the land is expropriated. This compensation is financially highly significant to them, as most relocatees generally belong to low to middle-income social groups.

In terms of the context, which has a significant influence on the experiences of relocatees, not only the features of place and people should be considered (e.g. physical, social and economic dimensions of neighbourhoods and demographic and socioeconomic statuses of residents), but also their positions within the macro context, i.e. the institutional, economic and social contexts (Goetz 2011; He 2012; Li, Kleinhans, and Van Ham 2018).

The institutional context, in particular the regulations and governance on urban redevelopment, is rapidly changing the interrelationships between different actors in urban restructuring (Shin 2016; Ren 2014). A key change concerns the evolution of the land expropriation and dwelling demolition regulations (Li, Kleinhans, and Van Ham 2018). There have been three versions of national regulations on urban redevelopment and forced relocation, which were enacted in 1991, 2001 and 2011 (The State Council of PRC 2001, 2011). Compared with the regulations issued in 1991 and 2001, the latest one specifically highlights the interests of residents. It sets out local government procedures for land expropriation from relocatees. It also enables residents to get involved in the decision-making of the compensation criteria and the project (Li, Kleinhans, and Van Ham 2018). Generally, relocatees have to choose between in-kind and monetary compensation. In-kind compensation means that relocatees receive alternative housing, while monetary compensation means that relocatees are given money for their dwellings. Local governments or developers determine the value of the dwellings slated for demolition, based on housing conditions (dwelling size and location of neighbourhood) and the local housing market (Chen and Lai 2013). Relocatees' choices concerning compensation directly affect the outcomes of forced relocation (Hu et al. 2015). If they choose in-kind compensation and the value of their new housing is higher than that of their old dwelling, they must pay the difference; if the value of the demolished housing is higher than that of the new one, relocatees then either receive additional financial compensation or are given other housing. This mechanism is based on the estimated market value of the housing, but it does not guarantee a certain quality of the housing. If relocatees choose monetary compensation, local governments and/or developers determine the compensation based on their assessment of the dwelling value. Obviously, the institutional context varies in different cities (see Section 4.2). This is due to differing local regulations, housing markets and investment levels of local governments. Some studies have observed that local governments and real estate developers cannot meet their promises to relocatees. An example is a change in post-relocation access to local social welfare systems. $\mathrm{Xu}$, Tang, and Chan (2011) showed that, in case of rural land requisition to the urban area of Shanghai, two social security systems were at stake: city social security (chengbao) and town social security (zhenbao). "In general, the city social security (chengbao) system affords greater well-being than town social security (zhenbao)." (ibid., 61)

The economic context, especially the local housing market situation, influences relocatees' expectations of and housing experiences during urban redevelopment. First, the amount of compensation is closely related to local housing prices. Second, housing access in current urban China is largely dependent on a household's income and status and 
whether people qualify for subsidized housing provided by the state or work units (Chen, Yang, and Wang 2014; Lee 2000; "Wang et al. 2012"). Currently, dwelling not only means home, but also an asset of growing financial importance because of rising housing prices. Therefore, the relocatees, especially those who are deprived and cannot move out of their declining neighbourhoods, need to rely on the offered compensation to improve their living and economic conditions. The economic situation of relocatees can influence their housing choices with regard to the location and the size of available dwellings and when they are going to be relocated. Third, many relocatees are mainly from inner-city neighbourhoods, work-unit (danwei) communities, urban villages, old public housing estates or suburban villages. These neighbourhoods have relatively high land value locations, but are in rundown physical conditions, making them a redevelopment priority for local governments and developers. Table 1 shows the types of neighbourhoods, location and their residential composition. Relocatees in these neighbourhoods are forced to move due to old inner-city redevelopment, shantytown redevelopment or public infrastructure construction.

At last, the social context, such as public opinions about redevelopment projects and the degree of public participation in the decision-making process, affects the experiences of relocatees (He 2012; Qian and He 2012; Weinstein and Ren 2009). The central government makes an effort to balance between economic growth and social equality (Li, 2015). If market failure erodes social stability, the market transition process will be intervened by the central government, as the social and political stability and economic development are underlying principles of central government's policy (Chen, Yang, and Wang 2014; He and Wu 2007; Wang et al. 2012). This can be traced from the evolution of the land expropriation regulations mentioned before (see also Li, Kleinhans, and Van Ham 2018).

\section{Understanding the Experiences of Relocatees during Three Stages of Forced Relocation}

Using the conceptual model (see Figure 1), this section reviews the experiences of relocatees in China during forced relocation across the three stages in the conceptual model, against the macro and micro contexts. The model includes key variables underlying the mechanisms of various relocation outcomes. Because the mechanisms between the key variables differ in and between each stage, we do not include all

Table 1. Targeted neighbourhoods for demolition.

\begin{tabular}{|c|c|c|c|c|}
\hline & $\begin{array}{c}\text { Traditional } \\
\text { inner-city } \\
\text { neighbourhood }\end{array}$ & $\begin{array}{l}\text { Danwei } \\
\text { community }\end{array}$ & $\begin{array}{l}\text { Urban } \\
\text { village }\end{array}$ & Suburban village \\
\hline Owners & $\begin{array}{l}\text { Inner-city } \\
\text { citizens/Local } \\
\text { housing bureau }\end{array}$ & $\begin{array}{l}\text { SOE or COE or } \\
\text { their employees }\end{array}$ & Rural farmers & Rural farmers \\
\hline $\begin{array}{l}\text { Ownership of } \\
\text { the land }\end{array}$ & $\begin{array}{c}\text { Stated-owned } \\
\text { land }\end{array}$ & $\begin{array}{l}\text { Stated-owned } \\
\text { land }\end{array}$ & $\begin{array}{l}\text { Collectively owned } \\
\text { land (by the villagers) }\end{array}$ & $\begin{array}{l}\text { Collectively } \\
\text { owned land (by } \\
\text { the villagers) }\end{array}$ \\
\hline Location & Inner-city centre & $\begin{array}{c}\text { Old industrial } \\
\text { area }\end{array}$ & $\begin{array}{l}\text { Between inner- } \\
\text { city centre and } \\
\text { urban periphery }\end{array}$ & Urban periphery \\
\hline
\end{tabular}

Source: Summarized from authors' observations and the literature, such as He (2012), He and Wu (2007), Hin and Xin (2011), Ma (2012), Wu (2004a, 2004b), Liu et al. (2017). 
mechanisms separately, as the model would become too complicated. However, the relationships between the key variables will be explained in each of the Sections 4.1, 4.2 and 4.3. We will also reveal the gaps in the literature that should be addressed in future studies of forced relocation in the Chinese context.

\subsection{Stage 1: The Pre-demolition Stage}

At this stage, relocatees have been informed about the impending demolition. Relocatees negotiate with developers or local governments about compensation (macro context), and they also grapple with issues such as what to agree to and when to sign compensation contracts. Some studies have found that relocatees have little influence on the decision-making process, while developers and local governments dominate the process and displace original low-income residents to the urban periphery (He and Wu 2005; He and Wu 2007; Ren 2014; Shin 2014). Tough disputes and conflicts may arise between relocatees, developers and local governments regarding redevelopment plans and compensation criteria (He 2012; Hin and Xin 2011; Hu et al. 2015). Some scholars argue that the essence of the interactions between different stakeholders at this stage concerns the mobilization of social relationships in the context of, and against the accumulation of space-based capital, and they regard the relocatees' strong response as a claim to "the right to the city", including the rights to the equitable distribution of the social benefits of development and to engage in decision-making (Qian and He 2012; Weinstein and Ren 2009).

However, these studies tend to overlook the individual experiences of relocatees, in particular their agency. Ownership of property and land-use rights are the only resources that residents can utilize against forced relocation (Zhang 2004). While relocatees can usually choose the compensation (in-kind or monetary) that they prefer, there is little research or evidence shows which option is the most popular. Relocatees' decisions on compensation choices depends on (1) the institutional context of forced relocation, and (2) the factors that are similar to regular movers, such as local housing market, their socio-economic and living arrangement. Many studies have shown how relocatees take their life course, affordability and the location of the relocation neighbourhoods into account when choosing compensation (An 2007; Ho 2013; Luo 2012; Ma 2012; Song 2015). For example, the amount of financial compensation is based on compensation criteria that are set by the real estate assessment company employed by local government or developers (Ma 2012).

Usually, relocatees expect more financial compensation than the local government and/or developer intend to provide (He and Asami 2014). In addition to direct confrontation with local governments or developers, relocatees use, sometimes illegal, strategies in an attempt to increase the amount of compensation (Ho 2013; Hu et al. 2015; Song 2015; He 2014). Relocatees can choose the timing of their signing of the contract that transfers their land-use right to the local government and/or developer (Ma 2012; Weinstein and Ren 2009; Shi and Zhu 2013). This may be influenced by various factors. For example, to promote the pace of demolition, local governments and developers use arguments, such as "the earlier you leave, the more benefits you will get; the later you leave, the fewer benefits you will get; refuse to leave, and you will get nothing" (Shi and Zhu 2013, 76). They also provide more 
positive incentives for those who sign the land-use right transfer contract at an early stage. As a result, some relocatees choose to sign the contract earlier. However, others wait until the last moment, because they believe that by doing so the local government and/or developer will offer them more compensation than other relocatees (Ho 2013; Ma 2012).

The second strategy is related to relocatees' networks (Ho 2013). The amount and the type of compensation are supposed to depend on the compensation criteria and the size of the demolished housing and/or relocation household. Some relocatees try to maximize compensation by looking for help from acquaintances (relatives, friends) working in related departments of local governments. It was reported that some staff members (e.g. those who work in a dwelling assessment company) were accused of corruption because they illegally increased the amount of compensation for some relocatees (Liaoning Daily 2015).

Thirdly, some relocatees attempt to increase their household size or construct illegal buildings (Luo 2012; Wu, Zhang, and Webster 2013). Last but not least, relocatees may organize online or real-world associations to exchange information or launch collective action against forced relocation (Erie 2012; He 2012; Song 2015; Wang 2009).

At this stage, the social dimension, i.e. relocatees' attachment to and interactions within their original neighbourhoods, also affects their response to forced relocation. Gilroy (2012) found that older residents in an old inner-city neighbourhood facing demolition had a strong attachment to the neighbourhood and were not willing to move. The elderly heavily depend on the long-term mutual help in their neighbourhoods due to the changes in living arrangements and family support in current urban China (Gilroy 2012). However, other research shows that strong attachment to the neighbourhood does not equate to a strong desire to stay. Wu $(2012,546)$ found that more established residents (those with a longer residential history and more highly educated residents) of old urban neighbourhoods show a lower willingness to stay and a preference to leave such neighbourhoods. The established residents deplore that many of their former neighbours moved out to suburban neighbourhoods where their children live, and that "there are more wailai renkou [outsiders] living here and everyone has different habits now" (Wu 2012, 546). This reveals an on-going transformation of old working-class communities and the dismantling of existing social networks and interactions of residents who are otherwise strongly attached to the area.

The physical conditions of neighbourhoods greatly affect residents' attachment to place in China (Li, Zhu, and Li 2012; Zhu, Breitung, and Li 2012). Zhu, Breitung, and Li (2012) found that intensive social interaction - a major source of attachment to place is regarded as less important now in urban China. These findings reveal that attachment to the neighbourhood in urban China has multiple dimensions (including social and physical spheres), and these different dimensions play different roles for different social groups and affect their housing behaviour differently.

Political-economic theories explain the mechanisms that induce forced relocation and urban restructuring, and demonstrate from a macro perspective why there are tensions and conflicts between different stakeholders at this stage. At the same time, the ways that relocatees cope with forced relocation are more complex and do not all end in confrontation. Current research mostly displays how a specific redevelopment project is 
implemented at this stage, and has neglected the coping strategies of relocatees (He 2007; Hin and Xin 2011). This may lead to ignorance regarding residents' potential agency during this stage. Individuals have different coping strategies and make different compensation choices, which also affect the experiences of relocatees in the following stages.

\subsection{Stage 2: The Transitional Period}

The transitional stage is often absent in European and American relocation scenarios. In the Western context, most people move directly into pre-existing properties elsewhere rather than having to wait for new properties to be built elsewhere. In China, at the transitional stage, residents leave their original neighbourhoods, but do not move immediately into relocation neighbourhoods. This stage is especially significant to those who choose in-kind compensation, because relocatees may have to wait for some time before they can move into the relocation neighbourhood. These residents need to find a temporary accommodation themselves to go through this phase. Local governments and/or developers usually promise to rehouse relocatees within a certain time (Song 2015; Chen and Lai 2013), and relocatees are given monetary compensation for renting temporary accommodation. Some local governments stipulate that the transitional period must not exceed a certain number of months. Nevertheless, in reality, the length of this stage greatly depends on whether the designated dwellings for rehousing are existing and readily available, or have not been completed. For example, in a redevelopment project in Shanghai, the relocation dwellings were still under construction (Jingan District Government 2015), and the relocatees therefore had to find a transitional dwelling and wait until the relocation dwellings were ready.

Very few studies focus on the experiences of relocatees at the transitional stage of forced relocation. Only sporadic news reports suggest that the long duration of the transitional stage can cause distress to relocatees (Nandu News 2015; People.cn 2013). This lack of interest in the literature does not mean this stage is not significant to relocatees. In fact, there are many uncertainties embedded in this period. Firstly, the time span of this stage varies, ranging from several months to several years, depending on the project and the related local regulations. The expected length of residence in a neighbourhood during this phase may affect residents' attachment to place, satisfaction, investment and neighbourliness. However, little is known about how the duration of the transitional stage affect the experience of relocatees across these dimensions.

Secondly, the time span may turn out to be quite different from what the local government or developer promised in the first stage, and hence from what was expected by the relocatees. In some cases, relocatees waited for more than five up to ten years due to delays in the construction of relocation dwellings (Xinhuanet 2014; Xinjing News 2013; People.cn 2013). In the meantime, relocatees have to rent dwellings, which creates challenges, in particular for people in disadvantaged social groups (the aged, disabled or people on low incomes). News reports have suggested that some aged relocatees have died while waiting to move into the relocation neighbourhoods because the transitional stage was very long (Nandu News 2015; Xinjing News 2013). Thirdly, it is unknown whether the compensation fee for the transitional stage can meet the needs 
of relocatees. In sum, very few studies address how the length and the uncertainties of the transitional stage affect relocatees.

When relocatees make their housing choices during this stage, they have to consider the constraints of forced relocation, such as the amount of rental compensation provided by the evictors and the duration of the transitional period. Their income, savings, and job location(s) can also influence their preferences about location, size and rental fee of their accommodation at this stage. Only sporadic evidence suggests that some relocatees choose to stay with their relatives or friends during this stage (Fang and Zhang 2003). Many questions are thus far from adequately studied, such as: What housing options do relocatees have at this stage? How and why do they make certain housing choices? How does their housing experience at this stage affect their subsequent housing behaviour and residential experience in the post-relocation stage? The uncertainty about the length of this stage means that many changes can occur to relocatees, such as changes in their household size and socio-economic situation. This means that the compensation choice they made in the pre-demolition stage might not fit their needs as the transitional stage proceeds.

The experiences of relocatees in this stage can also affect their general attitudes towards local governments and/or developers. Previous research has shown that the uncertain duration of the transitional period has negative effects on residents' trust in local governments (Li, Kleinhans, and Van Ham 2018). This in turn has consequences for relocatees' perceptions of forced relocation. In sum, the transitional stage has long been neglected with regard to relocatees' housing behaviours and coping strategy. It makes it impossible to achieve an overall evaluation on how the forced relocation process can affect relocatees because of the absence of related studies about this stage. In Section 5, we will argue how future research should address this gap.

\subsection{Stage 3: The Post-relocation Stage}

In Stage 3, the relocatees have been relocated to their final neighbourhoods. Most Chinese studies about this stage focus on residents who choose in-kind compensation, while there is little research about those who choose monetary compensation. This might be because that it is easier to track the former group than the latter one, as the former group (choosing in-kind compensation) is likely to move to a dwelling in the relocation neighbourhood and the latter one can relocate to anywhere they can afford.

By studying the experiences of relocatees who moved into relocation neighbourhoods, it is possible to trace and compare the foundations and effects of the various redevelopment projects. Since 1978, economic growth has become the overriding objective in China, and it has motivated local governments and developers to promote large-scale urban development and redevelopment for profit. Some studies argue that these large-scale developments have substantial social costs, because the residents were relocated to neighbourhoods with poor standards of housing and neighbourhood maintenance (Fang 2006; Gong 2012; He 2012; Li and Yuan 2008). Other studies have argued that the economic situation of some relocatees worsens because they are relocated to the urban periphery, which has poor accessibility to public facilities, thus increasing commuting costs and the time required to access job opportunities and/or the city centre (Day and Cervero 2010). 
However, other studies found positive effects. Some studies comparing pre-relocation living conditions with post-relocation living conditions, found that relocatees were satisfied with improved dwellings and neighbourhood conditions after their relocation (Li and Song 2009; Xia and Zhu 2013). By comparing different kinds of movers voluntary, involuntary - with stayers, some studies revealed that forced relocatees are more satisfied with their housing and neighbourhood conditions than stayers, and relatively less satisfied than voluntary movers (Day 2013; Li and Song 2009). In addition, the level of relocatees' satisfaction with their housing and neighbourhood conditions is not much lower than that of voluntary movers (Li and Song 2009).

The experiences of relocatees at this stage can also be differentiated in terms of their pre-relocation moving intentions and place attachment in relation to the (post-) relocation neighbourhood. Some studies have found that preceding demolition, residents show strong neighbourhood attachment and expressed a strong desire to stay in their old neighbourhoods, while after relocation, relocatees are less attached to their relocation neighbourhoods and their level of social interaction in the neighbourhood has also been reduced (He and Liu 2013). Luo (2012) further demonstrated that after the initial relocation, some relocatees decide to move back or closer to their original neighbourhoods, rather than stay in the relocation neighbourhood, because of familiarity with and access to better job and education opportunities in the original neighbourhood (Luo 2012).

In the United States and several Western European countries, urban restructuring and forced movement have been used as deliberate instruments to achieve more social mixing. Although there is no deliberate intention of development policies in China, large-scale urban redevelopments and forced relocation have generated similar outcomes (i.e. social mix). This is evident in the current national programme for Shantytown Redevelopment, in which the central government is encouraging local governments to purchase dwellings on the housing market rather than construct relocation neighbourhoods to compensate relocatees. As a result, forced movers and regular movers are more likely to live in the same neighbourhoods. Generally, this results in three types of relocation (destination) neighbourhoods, based on residential composition. Relocatees may be moved into:

(1) A relocation neighbourhood that only consists of relocatees from the same original redevelopment neighbourhood.

(2) A relocation neighbourhood that consists of relocatees from different original redevelopment neighbourhoods.

(3) A relocation neighbourhood that consists of relocatees from one or more redevelopment neighbourhoods, and of regular (voluntary) movers.

The experiences of relocatees in these different types of neighbourhoods vary. Some studies imply that relocation neighbourhoods with a concentration of relocatees with a low socioeconomic status are more likely to become deprived urban enclaves (Day 2013; Fang and Zhang 2003; Fang 2006; Gilroy 2012; He and Wu 2007; He 2010, 2012). Other studies have revealed conflicts between relocatees and regular movers, due to differences in terms of lifestyle, shared values and behaviour within the neighbourhood (Fang 2006; Gong 2012; Li and Yang 2010). Even when fighting for their common interests 
against real estate management companies, relocatees and regular movers sometimes cannot work together because of different social norms and behavioural patterns (Gong 2012; Li and Yang 2010).

The literature on the experiences of relocatees at stage 3 has shown that it has various dimensions; relocatees may simultaneously experience various post-relocation outcomes. Large-scale urban restructuring activities generate different neighbourhood types and different forms of organization in relocation neighbourhoods. These further affect the residential composition and the nature of interaction between different types of residents. In a mixed neighbourhood consisting of relocatees and regular movers, residents face issues, such as uneven spatial distribution of services and facilities (Fang 2006, 677; Song 2015). It is questionable whether this kind of social mix can help to generate social cohesion and social capital. Meanwhile, relocation neighbourhoods which purely consist of relocatees might also become concentration enclaves of lowincome residents.

\section{Conclusions and Implications for Future Research}

This paper aimed to gain greater insight into the experiences of relocatees during forced relocation in urban China by reviewing the existing literature. To enable a structured review approach, the paper proposed a conceptual model that considers the time sequence, context and individual experiences in various dimensions to explore the diversity, complexity and variety of experiences of relocatees in forced relocation in general. By using this model to analyze the existing literature, we have shown the relevance of the temporal feature of relocatees' experiences of different dimensions during the pre-demolition stage, the transitional stage and the post-relocation stage of urban redevelopment.

We believe that the time dimension embedded in the conceptual model is the first indispensable step to achieve a better understanding of relocatees' experiences. Current studies of China mostly treat forced relocation and urban redevelopment as a static and single event (Day and Cervero 2010; Fang 2006; He and Liu 2013; Hu et al. 2015). They mainly target the relocatees in the post-relocation stage to recall their pre-relocation experiences to evaluate the outcomes of forced relocation. This might lead to distorted retrospective accounts of their experiences and causes of their behavioural and emotional responses to forced relocation (Goetz 2013; Higgins and Stangor 1988). However, urban redevelopment and forced relocation often last for months or even years, during which period various incidents happen to relocatees in parallel with changing macro (social, economic and institutional) and micro (physical, psychological and socioeconomic) contexts. The proposed conceptual model captures the sequence of the events that occur to relocatees during urban redevelopment.

Overall, the experiences of relocatees are multifaceted and not necessarily unilaterally negative. Displacement is one possible effect of forced relocation. Simultaneously, neutral or significant positive effects may occur in combination with displacement. Hence, a balanced, critical perspective on the individual experiences of relocatees remains important (see also Kleinhans and Kearns 2013), helping to identify both advantages and disadvantages of the processes of forced relocation and urban restructuring. The conflicts and tensions between relocatees and other stakeholders show that 
relocatees may effectively cope with the process, mobilize resources and appeal to their rights to enjoy benefits of urban redevelopments. This is partly at odds with the general impression that the role of residents in urban redevelopment projects in China is passive. Residents' agency (see also Manzo, Kleit, and Couch 2008; Posthumus and Kleinhans 2014) also indicate that, to some extent and under specific conditions, consensus can emerge between residents, local governments and/or developers ( $\mathrm{Li}$, Kleinhans, and Van Ham 2018).

Using the conceptual model, the paper identified gaps in the existing literature. Firstly, most relocation studies overlook the pre-demolition and transitional stages. We have argued that the transitional stage is an essential part of forced relocation, especially in China, which requires more in-depth study focusing on relocatees' housing choices and coping strategies, especially in the light of the uncertainties of this stage.

Second, we found that most studies focus on relocatees' physical and economic experiences with regard to forced relocation, changes in dwelling and neighbourhood conditions, and their pre- and post-relocation income. However, existing research has significant shortcomings in analysing the experiences in the social, psychological and behavioural domains. As a result, the diverse roles, agency and strategies of relocatees are often overlooked. While some studies focus on relocatees' relationships with neighbours and the built environment, very few studies reveal how and why relocatees have certain social interactions within different neighbourhoods under the influence of impending or completed relocation.

The discussion of relocatees' experiences and mechanisms in this paper cannot cover all issues, as the outcomes are very diverse and time-dependent; the same applies to the macro and micro contexts. However, the identified gaps in the literature merit further research. In particular, the temporal feature of relocatees' experiences during urban redevelopment and lacking knowledge about the transitional stage merit further study. Ideally, this should be done through longitudinal panel surveys following relocatees throughout all stages. However, especially the transitional stage is notoriously difficult to monitor, because of attrition and inadequate register data. Frequent visits (by researchers), GIS tracking (of relocatees) and analysis might help to keep track of relocatees' temporary moves, enabling an interview approach to acquire insight in relocatees' experiences in this stage. Obviously, ethical issues and incentives for carrying GPS trackers must be carefully considered. Such a mixed-method research approach would be instrumental to identify more clearly how forced relocation and urban redevelopment differentially affect the well-being of the relocatees over time.

\section{Acknowledgments}

The authors are very grateful to the anonymous reviewers and the editor for their extensive and valuable suggestions regarding previous versions of this article.

\section{Disclosure statement}

No potential conflict of interest was reported by the authors. 


\section{Funding}

This work was supported by the China Scholarship Council [201304910351]; National Natural Science Foundation of China [41571152,41430635]; Marie Curie programme under the European Union's Seventh Framework Programme (FP/2007-2013)/Career Integration Grant [PCIG10-GA2011-303728 (CIG Grant NBHCHOICE, Neighbourhood choice, neighbourhood sorting, and neighbourhood effects)].

\section{References}

Allen, T. 2000. "Housing Renewal-Doesn't It Make You Sick?" Housing Studies 15 (3): 443-461. doi:10.1080/02673030050009276.

An, Z. 2007. "Development of Inhabitant's Family Structure and Living Pattern after House demolition-Case Study of Z Community in Shanghai." Master's thesis, East China Normal University.

Atkinson, R. 2000. "The Hidden Costs of Gentrification: Displacement in Central London." Journal of Housing and the Built Environment 15 (4): 307-326. doi:10.1023/A:1010128901782.

Bolt, G., and R. Van Kempen. 2010. "Dispersal Patterns of Households Who are Forced to Move: Desegregation by Demolition: A Case Study of Dutch Cities." Housing Studies 25 (2): 159-180. doi:10.1080/02673030903561834.

Cernea, M. 1997. "The Risks and Reconstruction Model for Resettling Displaced Populations." World Development 25 (10): 1569-1587. doi:10.1016/S0305-750X(97)00054-5.

Chen, J., and R. N. Lai. 2013. "Pricing Relocation-Redevelopment Projects for City Expansion: The Case in China." Real Estate Economics 41 (4): 925-957. doi:10.1111/reec.12017.

Chen, J., Z. Yang, and Y. P. Wang. 2014. "The New Chinese Model of Public Housing: A Step Forward or Backward?" Housing Studies 29 (4): 534-550. doi:10.1080/02673037.2013.873392.

Davidson, M. 2008. "Spoiled Mixture: Where Does State-Led Positive Gentrification End?" Urban Studies 45 (12): 2385-2405. doi:10.1177/0042098008097105.

Day, J. 2013. "Effects of Involuntary Residential Relocation on Household Satisfaction in Shanghai, China." Urban Policy and Research 31 (1): 93-117. doi:10.1080/08111146.2012.757736.

Day, J., and R. Cervero. 2010. "Effects of Residential Relocation on Household and Commuting Expenditures in Shanghai, China." International Journal of Urban and Regional Research 34 (4): 762-788. doi:10.1111/j.1468-2427.2010.00916.x.

Doff, W., and R. Kleinhans. 2010. "Residential Outcomes of Forced Relocation: Lifting a Corner of the Veil on Neighbourhood Selection." Urban Studies 48 (4): 661-680. doi:10.1177/ 0042098010366745.

Downing, T. E., and C. G. Downing. 2009. "Routine and Dissonant Cultures: A Theory about the Psycho-Socio-Cultural Disruptions of Involuntary Displacement and Ways to Mitigate Them without Inflicting Even More Damage." In Development and Dispossession, edited by A. OliverSmith, 225-253. Santa Fe: School for Advanced Research.

Erie, M. S. 2012. "Property Rights, Legal Consciousness and the New Media in China: The Hard Case of the 'Toughest Nail-House in History'." China Information 26 (1): 35-59. doi:10.1177/ $0920203 \times 11436164$.

Fang, K., and Y. Zhang. 2003. "Plan and Market Mismatch: Urban Redevelopment in Beijing during a Period of Transition." Asia Pacific Viewpoint 44 (2): 149-162. doi:10.1111/apv.2003.44.issue-2.

Fang, Y. 2006. "Residential Satisfaction, Moving Intention and Moving Behaviours: A Study of Redeveloped Neighbourhoods in Inner-City Beijing." Housing Studies 21 (5): 671-694. doi:10.1080/02673030600807217.

Freeman, L., and F. Braconi. 2004. "Gentrification and Displacement New York City in the 1990s." Journal of the American Planning Association 70 (1): 39-52.

Gilroy, R. 2012. "Physical Threats to Older People's Social Worlds: Findings from a Pilot Study in Wuhan, China." Environment and Planning A 44 (2): 458-476. doi:10.1068/a44291. 
Goetz, E. G. 2011. "Where Have All the Towers Gone? the Dismantling of Public Housing in US Cities." Journal of Urban Affairs 33 (3): 267-287. doi:10.1111/j.1467-9906.2011.00550.x.

Goetz, E. G. 2013. "Too Good to Be True? the Variable and Contingent Benefits of Displacement and Relocation among Low-Income Public Housing Residents." Housing Studies 28 (2): 235-252. doi:10.1080/02673037.2013.767884.

Goetz, E. G. 2016. "Resistance to Social Housing Transformation." Cities 57: 1-5. doi:10.1016/j. cities.2016.02.015.

Gong, H. 2012. "The Research on Differentiation of Grouping Order in Resettlement Community in $J$ City in Northeast of China as Example." Master's degree master's thesis, Jilin University.

Grier, G., and E. Grier. 1980. "Urban displacement: A reconnaissance." In Back to the City: In Neighbourhood Renovation, edited by S. B. Laska and D. Spain, 252-268. New York: Pergamon.

He, S. 2007. "State-Sponsored Gentrification under Market Transition the Case of Shanghai." Urban Affairs Review 43 (2): 171-198.

He, S. 2010. "New-Build Gentrification in Central Shanghai: Demographic Changes and Socioeconomic Implications." Population, Space and Place 16 (5): 345-361. doi:10.1002/psp.548.

He, S. 2012. "Two Waves of Gentrification and Emerging Rights Issues in Guangzhou, China." Environment and Planning A 44 (12): 2817-2833. doi:10.1068/a44254.

He, S., and F. Wu. 2005. "Property-Led Redevelopment in Post-Reform China: A Case Study of Xintiandi Redevelopment Project in Shanghai." Journal of Urban Affairs 27 (1): 1-23.

He, S., and F. Wu. 2007. "Socio-Spatial Impacts of Property-Led Redevelopment on China's Urban Neighbourhoods." Cities 24 (3): 194-208. doi:10.1016/j.cities.2006.12.001.

He, S., and Z. Liu. 2013. "A Follow-On Study on the Impact of Urban Redevelopment on Local Residents Induced by the Asian Games: An Investigation in the Three Affected Communities in Guangzhou." In Chinese Geographical Research 32 (3): 243-275.

He, X. 2014. "Maintaining Stability by Law: Protest-Supported Housing Demolition Litigation and Social Change in China." Law and Social Inquiry-Journal of the American Bar Foundation 39 (4): 849-873. doi:10.1111/Isi.12064.

He, Z., and Y. Asami. 2014. "How Do Landowners Price Their Lands during Land Expropriation and the Motives behind It: An Explanation from a WTA/WTP Experiment in Central Beijing." Urban Studies 51 (2): 412-427. doi:10.1177/0042098013492227.

Higgins, E. T., and C. Stangor. 1988. "A "Change-Of-Standard" Perspective on the Relations among Context, Judgment, and Memory." Journal of Personality and Social Psychology 54 (2): 181-192.

Hin, L. L., and L. Xin. 2011. "Redevelopment of Urban Villages in Shenzhen, China - An Analysis of Power Relations and Urban Coalitions." Habitat International 35 (3): 426-434. doi:10.1016/j. habitatint.2010.12.001.

Ho, C. Y. 2013. "Bargaining Demolition in China: A Practice of Distrust." Critique of Anthropology 33 (4): 412-428. doi:10.1177/0308275x13501902.

Hu, Y., P. Hooimeijer, G. Bolt, and D. Sun. 2015. "Uneven Compensation and Relocation for Displaced Residents: The Case of Nanjing." Habitat International 47: 83-92.

Jingan District Government. 2015. "The Scheme for Dwelling Expropriation and Compensation for the Old Inner City Redevelopmnet Project at No.73 Street in Jingan District." Jingan District-level Government, Accessed 6 August. http://www.jingan.gov.cn/xxgk/016023/016023002/20150814/ a7904748-b69d-4ad4-96d2749535df689d.html;http://www.jingan.gov.cn/xxgk/016001/ 016001001/20150817/69939629-2783-4004-8205-d42d1e8ba3a2.html.

Kearns, A., and P. Mason. 2013. "Defining and Measuring Displacement: Is Relocation from Restructured Neighbourhoods Always Unwelcome and Disruptive?" Housing Studies 28 (2): 177-204. doi:10.1080/02673037.2013.767885.

Kleinhans, R. 2003. "Displaced but Still Moving Upwards in the Housing Career? Implications of Forced Residential Relocation in the Netherlands." Housing Studies 18 (4): 473-499. doi:10.1080/ 02673030304248.

Kleinhans, R., and A. Kearns. 2013. "Neighbourhood Restructuring and Residential Relocation: Towards a Balanced Perspective on Relocation Processes and Outcomes." Housing Studies 28 (2): 163-176. doi:10.1080/02673037.2013.768001. 
Kleinhans, R., and W. Van der Laan Bouma-Doff. 2008. “On Priority and Progress: Forced Residential Relocation and Housing Chances in Haaglanden, the Netherlands." Housing Studies 23 (4): 565587. doi:10.1080/02673030802101641.

La Grange, A., and F. Pretorius. 2016. "State-Led Gentrification in Hong Kong." Urban Studies 53 (3): 506-523.

Lee, J. 2000. "From Welfare Housing to Home Ownership: The Dilemma of China's Housing Reform." Housing Studies 15 (1): 61-76.

Li, K. 2015. Li Keqiang: Peng-hu-qu Wenti Bujiejue Hetan Shehui Gongping (Li Keqiang: How can we achieve social justice if the shantytown problems are not solved). http://www.gov.cn/ xinwen/2015-06/17/content_2880958.htm

Li, Q., and L. Yang. 2010. Residential Differentiation and Social Distance. Social Sciences of Beijing In Chinese 1: 4-11.

Li, S-M., and Y.L. Song. 2009. "Redevelopment, Displacement, Housing Conditions, and Residential Satisfaction: A Study of Shanghai." Environment and Planning A 41 (5): 1090-1108. doi:10.1068/ a4168.

Li, S-M., Y. Zhu, and L. Li. 2012. "Neighbourhood Type, Gatedness, and Residential Experiences in Chinese Cities: A Study of Guangzhou." Urban Geography 33 (2): 237-255.

Li, X., and X. Yuan. 2008. "Rethinking Danwei Communities." Sichuan Building Science 34 (2): 197199.

Li, X., R. Kleinhans, and M. Van Ham. 2018. "Shantytown Redevelopment Projects: State-Led Redevelopment of Declining Neighbourhoods under Market Transition in Shenyang, China." Cities 73: 106-116.

Liaoning Daily. 2015. "Within 1 Month Liaoning Province Reports 23 Issues that Violate the 'Ethos'." CPC NEWS, Accessed 14 October 2017. http://fanfu.people.com.cn/n/2015/1014/c6437127696907.html

Liu, Y., F. Wu, Y. Liu, and Z. Li. 2017. "Changing Neighbourhood Cohesion under the Impact of Urban Redevelopment: A Case Study of Guangzhou, China." Urban Geography 38 (2): 266-290.

Luo, Y. 2012. "Institutional Arrangements and Individual Action: TheSpontaneous Moving Back of Urban Inhabitants of Resettlement and Space Reconstruction of the Original Community" Master thesis, East China Normal University.

Ma, J. 2012. "The Study on Farmers' Attitude and Behaviour of Different Relocation Models." Master thesis, Dongbei University of Finance and Economics.

Manzo, L. C., R. G. Kleit, and D. Couch. 2008. "Moving Three Times Is like Having Your House on Fire Once": The Experience of Place and Impending Displacement among Public Housing Residents." Urban Studies 45 (9): 1855-1878.

Marcuse, P. 1985. "Gentrification, Abandonment, and Displacement: Connections, Causes, and Policy Responses in New York City." Washington University Journal of Urban and Contemporary Law 28: 195.

Nandu News. 2015. "How Come the Relocation Lasts for 12 Years for 200 Villagers in Xiacun Village in Zhuhai City?" Nandu News, Accessed 12 January http://paper.oeeee.com/nis/201501/19/ 318555.html.

Newman, K., and E. K. Wyly. 2006. "The Right to Stay Put, Revisited: Gentrification and Resistance to Displacement in New York City." Urban Studies 43 (1): 23-57.

People.cn. 2013. "Haven't Been Relocated for More than 10 Years". People.cn, Accessed 25 February 2018.http://leaders.people.com.cn/n/2013/0225/c178291-20584614.html.

Popkin, S. J., D. K. Levy, L. E. Harris, J. Comey, M. K. Cunningham, and L. F. Buron. 2004. “The HOPE VI Program: What about the Residents?" Housing Policy Debate 15 (2): 385-414. doi:10.1080/ 10511482.2004.9521506.

Posthumus, H., and R. Kleinhans. 2014. "Choice within Limits: How the Institutional Context of Forced Relocation Affects Tenants' Housing Searches and Choice Strategies." Journal of Housing and the Built Environment 29 (1): 105-122. doi:10.1007/s10901-013-9353-6.

Qian, J., and S. He. 2012. "Rethinking Social Power and the Right to the City Amidst China's Emerging Urbanism." Environment and Planning A 44 (12): 2801-2816. doi:10.1068/a44373. 
Ren, X. 2014. "The Political Economy of Urban Ruins: Redeveloping Shanghai." International Journal of Urban and Regional Research 38 (3): 1081-1091. doi:10.1111/1468-2427.12119.

Scudder, T., and E. Colson. 1982. "From Welfare to Development: A Conceptual Framework for the Analysis of Dislocated People." In Involuntary Migration and Resettlement, edited by A. Hansen and A. Ohver-Smith, 267-287. Boulder: Westview Press.

Shi, J.G., and J. Zhu. 2013. Behaviour of Relocatees from a Game View. Urban Problems In Chinese 4: 72-77.

Shin, H. B. 2014. "Urban Spatial Restructuring, Event-Led Development and Scalar Politics." Urban Studies 51 (14): 2961-2978. doi:10.1177/0042098013515031.

Shin, H. B. 2016. "Economic Transition and Speculative Urbanisation in China: Gentrification versus Dispossession." Urban Studies 53 (3): 471-489.

Sichuan News. 2009. "Report about the Demolition and Self-Burning Event in Chengdu City." Sichuan News, Accessed 3 September 2017.http://scnews.newssc.org/system/2009/12/03/ 012464005.shtml.

Song, J. 2015. "Official Relocation and Self-Help Development: Three Housing Strategies under Ambiguous Property Rights in China's Rural Land Development." Urban Studies 52 (1): 121-137. doi:10.1177/0042098014524612.

The State Council of PRC. 2001 "The Regulation on the Management of the Demolition of Urban Dwellings." The State Council of PRC. Accessed 13 June 2017. http://www.gov.cn/gongbao/ content/2001/content_60912.htm.

The State Council of PRC. 2011. "The Regulation on the Expropriation and Compensation of Dwellings on the State-Owned Land" The State Council of PRC. Accessed 21 January 2018. http://www.gov.cn/flfg/2011-01/21/content_1791480.htm.

The State Council of PRC. 2013. "The Suggestions of the State Council on Accelerating the Slum Clearance and Upgrade Projects." The State Council of PRC. Accessed 12 July 2017. http://www. gov.cn/zwgk/2013-07/12/content_2445808.htm.

Wang, L. 2009. "The Actual Selection of Interests Expression of Urban Relocated Residents: A CaseStudy of Relocated Residents' Campaign in B District of H City." Master thesis, Northeast Normal University.

Wang, YP, L. Shao, A. Murie, and J. Cheng. 2012. "The Maturation of the Neo-Liberal Housing Market in Urban China." Housing Studies 27 (3): 343-359.

Weinstein, L., and X. Ren. 2009. "The Changing Right to the City: Urban Renewal and Housing Rights in Globalizing Shanghai and Mumbai." City \& Community 8 (4): 407-432.

Wu, F. 2004a. "Intra-Urban Residential Relocation in Shanghai: Modes and Stratification." Environment and Planning A 36 (1): 7-25.

Wu, F. 2004b. "Residential Relocation under Market-Oriented Redevelopment: The Process and Outcomes in Urban China." Geoforum 35 (4): 453-470. doi:10.1016/j.geoforum.2003.10.001.

Wu, F. 2012. "Neighbourhood Attachment, Social Participation, and Willingness to Stay in China's Low-Income Communities." Urban Affairs Review 48 (4): 547-570.

Wu, F., F. Zhang, and C. Webster. 2013. "Informality and the Development and Demolition of Urban Villages in the Chinese Peri-Urban Area." Urban Studies 50 (10): 1919-1934. doi:10.1177/ 0042098012466600.

Xi, J., and S.-S. Hwang. 2011. "Relocation Stress, Coping, and Sense of Control among Resettlers Resulting from China's Three Gorges Dam Project." Social Indicators Research 104 (3): 507-522. sea

Xia, Y., and X. Zhu. 2013. "The Evaluation of Urban Forced Movers' Community Satisfaction-A Case Study of Nanjing." In Chinese Scientia Geographica Sinica .33 (8): 918-925.

Xinhuanet. 2014. "Thousands of Relocation Households Have Not Been Rehoused. Why Has the Key Shantytown Redevelopment Project Been Ceased for Many Years?" Xinhuanet, Accessed 12 April 2017.http://news.xinhuanet.com/fortune/2014-04/21/c_1110327303.htm.

Xinjing News. 2013. "180 Relocatee Households Have Been Drifting for 13 Years in Taiyuan City 50 Relocatees Cannot Be Rehoused until They Passed Away." Xinhuanet, Accessed 1 October 2017. http://www.hb.xinhuanet.com/2013-10/01/c_117582191.htm. 
Xu, Y., B-S. Tang, and E. H. W. Chan. 2011. "State-Led Land Requisition and Transfor- Ation of Rural Villages in Transitional China." Habitat International 35 (1): 57-65. doi:10.1016/j. habitatint.2010.03.002.

Zhang, L. 2004. "Forced from Home: Property Rights, Civic Activism, and the Politics of Relocation in China." Urban Anthropology 33 (2-4): 247-281.

Zhu, Y., W. Breitung, and S-M. Li. 2012. "The Changing Meaning of Neighbourhood Attachment in Chinese Commodity Housing Estates: Evidence from Guangzhou." Urban Studies 49 (11): 24392457. doi:10.1177/0042098011427188. 